\title{
Impaired training-induced adaptation of blood pressure in COPD patients: implication of the muscle capillary bed
}

This article was published in the following Dove Press journal:

International Journal of COPD

22 September 2016

Number of times this article has been viewed

\author{
Fares Gouzi ${ }^{1,2}$ \\ Jonathan Maury ${ }^{1,3}$ \\ François Bughin ${ }^{1,2}$ \\ Marine Blaquière ${ }^{1,2}$ \\ Bronia Ayoub ${ }^{1,2}$ \\ Jacques Mercier ${ }^{1,2}$ \\ Antonia Perez-Martin ${ }^{4,5}$ \\ Pascal Pomiès' \\ Maurice Hayot ${ }^{1,2}$ \\ 'PhyMedExp, INSERM UI 046, \\ CNRS UMR 92।4, University of \\ Montpellier, ${ }^{2}$ Department of Clinical \\ Physiology, Montpellier University \\ Hospital, Montpellier, ${ }^{3}$ Pulmonary \\ Rehabilitation Center "La Solane", \\ 5 Santé Group, Osséja, ${ }^{4}$ Dysfunction \\ of Vascular Interfaces Laboratory, \\ EA 2992, University of Montpellier, \\ ${ }^{5}$ Department of Vascular Medicine \\ and Investigations, Nîmes University \\ Hospital, Nîmes, France
}

Correspondence: Fares Gouzi Department of Clinical Physiology, Montpellier University Hospital, 37I, Avenue du Doyen G Giraud, F-34295 Montpellier, France $\mathrm{Tel}+33467335908$ Fax +33467335923 Email f-gouzi@chu-montpellier.fr
Background and aims: Targeting the early mechanisms in exercise-induced arterial hypertension (which precedes resting arterial hypertension in its natural history) may improve cardiovascular morbidity and mortality in COPD patients. Capillary rarefaction, an early event in COPD before vascular remodeling, is a potential mechanism of exercise-induced and resting arterial hypertension. Impaired training-induced capillarization was observed earlier in COPD patients; thus, this study compares the changes in blood pressure (BP) during exercise in COPD patients and matches control subjects (CSs) after a similar exercise training program, in relationship with muscle capillarization.

Methods: Resting and maximal exercise diastolic pressure (DP) and systolic pressure (SP) were recorded during a standardized cardiopulmonary exercise test, and a quadriceps muscle biopsy was performed before and after training.

Results: A total of $35 \mathrm{CSs}$ and $49 \mathrm{COPD}$ patients (forced expiratory volume in 1 second $=54 \% \pm 22 \%$ predicted) completed a 6 -week rehabilitation program and improved their symptom-limited maximal oxygen uptake $\left(\mathrm{VO}_{2 \mathrm{SL}}: 25.8 \pm 6.1 \mathrm{~mL} / \mathrm{kg}\right.$ per minute vs $27.9 \mathrm{~mL} / \mathrm{kg}$ per minute and $17.0 \pm 4.7 \mathrm{~mL} / \mathrm{kg}$ per minute vs $18.3 \mathrm{~mL} / \mathrm{kg}$ per minute; both $P<0.001$ ). The improvement in muscle capillary-to-fiber $(\mathrm{C} / \mathrm{F})$ ratio was significantly greater in CSs vs COPD patients $(+11 \% \pm 9 \%$ vs $+23 \% \pm 21 \% ; P<0.05)$. Although maximal exercise BP was reduced in CSs (DP: $89 \pm 10 \mathrm{mmHg}$ vs $85 \pm 9 \mathrm{mmHg} ; P<0.001 / \mathrm{SP}$ : $204 \pm 25 \mathrm{mmHg}$ vs $196 \pm 27 \mathrm{mmHg}$; $P<0.05$ ), it did not change in COPD patients (DP: $94 \pm 14 \mathrm{mmHg}$ vs $97 \pm 16 \mathrm{mmHg} ; P=0.46$ / SP: $202 \pm 27 \mathrm{mmHg}$ vs $208 \pm 24 \mathrm{mmHg} ; P=0.13)$. The change in muscle $\mathrm{C} / \mathrm{F}$ ratio was negatively correlated with maximal exercise SP in CSs and COPD patients $(r=-0.41 ; P=0.02)$.

Conclusion: COPD patients showed impaired training-induced BP adaptation related to a change in muscle capillarization, suggesting the possibility of blunted angiogenesis.

Keywords: angiogenesis, hypertension, pulmonary rehabilitation

\section{Introduction}

COPD is a composite disease associated with comorbidities. Systemic arterial hypertension (HTA) ${ }^{1}$ occurs in 40\%-60\% of COPD patients, ${ }^{2,3}$ increasing their risk of cardiovascular disease and death. ${ }^{4-6}$ Identifying the early mechanisms of HTA onset might therefore improve the cardiovascular morbidity and mortality in these patients. ${ }^{7}$ Before vascular remodeling occurs, a reduced capillary bed is an early mechanism of HTA. ${ }^{8}$ Exercise training studies have confirmed the link between blood pressure (BP) and the capillary bed in both animal models ${ }^{9}$ and healthy/hypertensive subjects. ${ }^{10,11}$

Early capillary bed reduction may first be revealed by exercise-induced HTA (defined as systolic pressure $[\mathrm{SP}]>210 \mathrm{mmHg}$ for males and $>190 \mathrm{mmHg}$ for females during 
exercise $^{12}$ ), because it is a forerunner of resting HTA. It is associated with masked HTA, ${ }^{13}$ precedes HTA onset,,${ }^{14}$ and predicts future cardiovascular events, irrespective of resting BP. ${ }^{15}$ In addition, capillary rarefaction contributes to exerciseinduced HTA in both healthy ${ }^{16}$ and hypertensive subjects. ${ }^{17}$

Capillary rarefaction has been reported in COPD patients ${ }^{18,19}$ and is correlated with disease severity. ${ }^{20} \mathrm{~A}$ decline in the angiogenic potential starts from the mild stages of COPD,${ }^{21}$ indicating that capillary rarefaction is an early mechanism in HTA of these patients. Given our report of their blunted muscle angiogenic response to exercise training, ${ }^{18}$ improved BP after training should not be expected in COPD patients. Yet, the blunted improvement in resting $\mathrm{BP}^{22-24}$ has been imputed to preexistent vascular remodeling. ${ }^{23}$ Therefore, to determine the exact role of capillary rarefaction in COPD patients, this study compared the changes in exercise BP in COPD patients without declared vascular disease and matched control subjects (CSs) following a similar training program.

\section{Patients and methods}

\section{Study population}

From March 2008 to May 2015, we conducted three prospective studies of the exercise training effects on COPD patients vs CSs (Montpellier Sud-Mediterranée IV Ethics Committee numbers: 2008-EESSS-V2, 2009-04-BPCO-V2, and 2011-A00842-39). Informed written consent was obtained from all the subjects. COPD was confirmed according to the Global Initiative for Obstructive Lung Disease criteria (dyspnea, chronic cough, or sputum production and/or a history of exposure to risk factors for the disease, and postbronchodilator forced expiratory volume in 1 second $\left[\mathrm{FEV}_{1}\right] /$ forced vital capacity $<70 \%{ }^{25}$ ). Exclusion criteria included other respiratory diagnosis, decompensated comorbidity, exacerbation in the last 3 months, earlier participation in an exercise training program, and history of artery disease (coronary artery disease, peripheral artery disease, stroke, etc) or diabetes. Subjects from the age of 50 years to 75 years with normal pulmonary function were tested at INSERM U-1046, CHU Montpellier, France, or "La Solane" Pulmonary Rehabilitation Center in Osseja, France. The clinical trial was registered at https://ClinicalTrials.gov/ (NCT01183039, NCT01942889, and NCT02040363).

\section{$\mathrm{BP}$ and exercise test measurement}

Participants performed an incremental individualized cycloergometric test to determine symptom-limited oxygen uptake $\left(\mathrm{VO}_{2 \mathrm{SL}}\right)$ on an electrically braked cycle ergometer (Ergoselect 200P; Ergolyne, Bitz, Germany) as described earlier. ${ }^{18}$
Resting SP and diastolic pressure (DP) were recorded after 3-5 minutes with a stabilized heart rate (HR), while the subject remained seated on the ergometer. Following a validated methodology, we recorded BP noninvasively every 3 minutes and immediately at the end of exercise with an automated sphygmomanometer; ${ }^{26}$ the investigator manually verified it if it was aberrant or elevated $>190 \mathrm{mmHg}$. HR was assessed from the electrocardiogram and verified using a pulse oximeter. Maximal BP was accepted if obtained $<2$ minutes before recovery or $<1$ minute after recovery, and if the workload increment protocol and timing for the pre- and posttraining maximal BP measurements were similar and verified by an experienced physiologist. Mean arterial pressure (MAP) was calculated according to the following formula:

$$
\mathrm{MAP}=\mathrm{DP}+\frac{1}{3}(\mathrm{SP}-\mathrm{DP})
$$

Pulsed pressure ${ }^{17}$ was calculated as the difference between SP and DP.

\section{Functional assessments}

All participants completed the Voorrips physical activity questionnaire ${ }^{27}$ and underwent full spirometry using plethysmography and a 6-minute walking test, according to the American Thoracic Society/European Respiratory Society statements and as described elsewhere. ${ }^{18}$

\section{Muscle biopsy and capillary bed assessment} Muscle biopsies were performed in the "vastus lateralis" of the quadriceps before the exercise program and 48 hours after the last training session, with our usual methodology as described earlier. ${ }^{28}$ Muscle capillarization was assessed after immunohistochemistry on frozen sections (10 $\mu \mathrm{m}$ thickness) from the muscle biopsies, using Hoechst for the nuclei and antibody specific to CD31 (\#550389; BD Bioscience, Franklin Lakes, NJ, USA) as described earlier. ${ }^{18}$ Capillary density and capillary-to-fiber $(\mathrm{C} / \mathrm{F})$ ratio (a validated marker for the $\mathrm{C} / \mathrm{F}$ interface ${ }^{18}$ ) were determined after counting capillaries on 1-2 cryosections from each muscle biopsy and in quintuplet on each of these cryosections.

\section{Exercise training}

A minimum of 20 sessions of endurance exercise (stationary cycling, walking) was conducted over 4-6 weeks. Exercise was performed at the intensity of each subject's ventilatory threshold and individualized by targeting the corresponding HR with a HR monitor. ${ }^{29}$ Each session lasted 
1 hour 30 minutes, with 45 minutes of endurance training (10 minutes at the intensity of the ventilatory threshold followed by 5 minutes of active recovery, which was repeated three times) followed by 30 minutes of strength-building exercise (eight to ten exercises, with sets of ten to 15 repetitions, at $40 \%$ of the isotonic one-repetition maximum). ${ }^{30}$

\section{Statistical analysis}

Categorical variables are described as numbers and proportions. All continuous variables were tested for normality. They are expressed as mean \pm SD if normally distributed, and as median \pm interquartile range $(25 \%-75 \%)$ if not. Baseline comparisons between CSs and COPD patients were made via Student's $t$-tests (normally distributed variables) or the Mann-Whitney $U$-test (nonnormal distribution) for continuous variables and the Fisher's exact test for categorical variables. Training, group effects, and interactions were tested by mixed linear regression modeling. Pearson's coefficients describe the correlations. Results were statistically significant when $P \leq 0.05$. Statistical analysis was performed using the R statistical package, Version 2.7.0.

\section{Results}

\section{Characteristics of the study subjects}

Table 1 presents the baseline characteristics of 35 CSs and 49 COPD patients. COPD patients differed significantly for

Table I Baseline characteristics of control subjects and COPD patients

\begin{tabular}{|c|c|c|c|}
\hline Characteristics & $\begin{array}{l}\text { Controls } \\
\text { (pretraining) }\end{array}$ & $\begin{array}{l}\text { COPD } \\
\text { (pretraining) }\end{array}$ & $P$-value \\
\hline Patients, $\mathrm{n}$ & 35 & 49 & \\
\hline Age (years) & $62.1 \pm 5.8$ & $61.5 \pm 7.9$ & NS \\
\hline $\operatorname{Sex}(M / F), n$ & $18 / 17$ & $30 / 19$ & 1.00 \\
\hline $\mathrm{FEV}_{1}$ (\% pred) & $107 \pm 14$ & $54 \pm 22$ & $<0.001$ \\
\hline BMI $\left(\mathrm{kg} / \mathrm{m}^{2}\right)$ & $25.9 \pm 2.8$ & $25.5 \pm 4.5$ & NS \\
\hline $\begin{array}{l}\text { Tobacco smoke } \\
\text { (pack-years) }\end{array}$ & $5.5 \pm 10.4$ & $44.3 \pm 19$ & $<0.001$ \\
\hline Voorrips score & $4.6(2.4-7.1)$ & $4.1(2.2-7.2)$ & NS \\
\hline 6MWD (m, \% pred) & $\begin{array}{l}628 \pm 75 \\
97 \pm 12\end{array}$ & $\begin{array}{l}505 \pm 115 \\
78 \pm 18\end{array}$ & $<0.001$ \\
\hline $\begin{array}{l}\mathrm{VO}_{2 \mathrm{SL}}(\mathrm{mL} / \mathrm{kg} / \mathrm{min} \text {, } \\
\% \text { pred })\end{array}$ & $\begin{array}{l}25.8 \pm 6.2 \\
107 \pm 14\end{array}$ & $\begin{array}{l}17.4 \pm 4.7 \\
68 \pm 19\end{array}$ & $<0.001$ \\
\hline Resting SP (mmHg) & $132 \pm 18$ & $132 \pm 23$ & 0.96 \\
\hline Resting DP (mmHg) & $80 \pm 10$ & $79 \pm 11$ & 0.66 \\
\hline Resting HR (bpm) & $81 \pm 12$ & $87 \pm 18$ & 0.09 \\
\hline Maximum SP (mmHg) & $203 \pm 25$ & $200 \pm 31$ & 0.63 \\
\hline Maximum DP (mmHg) & $89 \pm 10$ & $94 \pm 14$ & 0.09 \\
\hline Maximum HR (bpm) & $160 \pm 13$ & $137 \pm 20$ & $<0.001$ \\
\hline
\end{tabular}

Note: Data are presented as mean \pm SD, median (IQR: $25 \%-75 \%$ ), or number. Abbreviations: BMI, body mass index; DP, diastolic pressure; $F$, female; $F E V_{1}$, forced expiratory volume in I second; $H R$, heart rate; $I Q R$, interquartile range; $M$, male; min, minute; 6MWD, 6-minute walking distance; $\mathrm{VO}_{2 \mathrm{LL}}$, symptom-limited oxygen uptake; pred, predicted; SP, systolic pressure; NS, not significant.
$\mathrm{FEV}_{1}$ and past tobacco smoking but were similar to CSs for other confounding factors of hypertension (age, body mass index [BMI], and physical activity level). COPD patients had reduced exercise capacity assessed by $\mathrm{VO}_{2 \mathrm{SL}}(-32 \%$; $P<0.001)$ and 6-minute walking distance (6MWD; $-20 \%$; $P<0.001)$. The prevalence of resting hypertension was lower in CSs vs COPD patients $(23 \%$ vs $45 \%$; $P<0.05)$. The prevalence of exercise-induced hypertension was not statistically different between groups ( $58 \%$ vs $54 \% ; P=1.00)$. However, maximum HR was higher in $\mathrm{CSs}$, indicating lower cardiocirculatory stress at $\mathrm{VO}_{2 \mathrm{SL}}$ in the ventilatory-limited COPD patients.

Baseline muscle capillarization was assessed in a subgroup of 19 COPD patients and $17 \mathrm{CSs}$ who were representative of the whole population (Table 2) and confirmed the muscle capillary rarefaction in COPD patients vs $\mathrm{CSs}(\mathrm{C} / \mathrm{F}$ ratio: $1.90 \pm 0.42$ vs $1.57 \pm 0.26 ; P<0.01)$.

\section{Effect of the training program}

Training significantly improved exercise capacity in CSs and COPD patients in terms of 6MWD $(628 \pm 75 \mathrm{~m}$ vs $660 \pm 64 \mathrm{~m}$ and $505 \pm 115 \mathrm{~m}$ vs $541 \pm 114 \mathrm{~m}$, respectively; $P<0.001)$ and $\mathrm{VO}_{2 \mathrm{SL}}(25.8 \pm 6.1 \mathrm{~mL} / \mathrm{kg}$ per minute vs $27.9 \mathrm{~mL} / \mathrm{kg}$ per minute and $17.0 \pm 4.7 \mathrm{~mL} / \mathrm{kg}$ per minute vs $18.3 \mathrm{~mL} / \mathrm{kg}$ per minute, respectively; $P<0.001)$. Although weight remained stable in CSs $(74.5 \pm 11.6 \mathrm{~kg}$ vs $74.7 \pm 11.9 \mathrm{~kg} ; P=0.41)$, it decreased in COPD patients $(71.3 \pm 13.9 \mathrm{~kg}$ vs $70.9 \pm 13.9 \mathrm{~kg} ; P<0.01)$.

The improvement in muscle $\mathrm{C} / \mathrm{F}$ ratio was significant in both groups $(+11 \% \pm 9 \%[\mathrm{n}=19]$ and $+23 \% \pm 21 \%[\mathrm{n}=17]$, $P<0.05$; Figure 1) and correlated with improved maximal oxygen uptake $(r=0.45 ; P<0.01)$. However, the significant interaction between group and time $(P<0.05)$ indicated higher training-induced capillarization in CSs vs COPD patients.

\section{Training-induced BP changes in CSs and COPD patients}

Figure 2 presents the absolute changes in resting and maximal exercise BP. Analysis of resting BP revealed no significant posttraining change in either CSs (DP: $80 \pm 10 \mathrm{mmHg}$ vs $77 \pm 7 \mathrm{mmHg} ; P=0.42 / \mathrm{SP}: 132 \pm 18 \mathrm{mmHg}$ vs $125 \pm 15 \mathrm{mmHg}$; $P=0.07$ ) or COPD patients (DP: $79 \pm 11 \mathrm{mmHg}$ vs $80 \pm 12 \mathrm{mmHg}$; $P=0.89 / \mathrm{SP}: 132 \pm 23 \mathrm{mmHg}$ vs $134 \pm 20 \mathrm{mmHg} ; P=0.99$ ). Resting BP showed no significant interaction between group and time ( $P=0.31$ and $P=0.13$, for DP and SP, respectively), indicating no significant training effect on BP in COPD patients. Resting HR remained unchanged in both groups (CSs: $81 \pm 12$ bpm vs $78 \pm 8$ bpm; $P=0.27$, and COPD patients: $87 \pm 19$ bpm vs $83 \pm 12$ bpm; $P=0.07)$. 
Table 2 Comparisons of the baseline characteristics of the entire group of control subjects and the entire group of COPD patients and subgroups with muscle biopsy

\begin{tabular}{|c|c|c|c|c|c|c|}
\hline Characteristics & $\begin{array}{l}\text { All } \\
\text { controls }\end{array}$ & $\begin{array}{l}\text { Controls + } \\
\text { biopsy }\end{array}$ & $P$-value & All COPD & $\begin{array}{l}\text { COPD + } \\
\text { biopsy }\end{array}$ & $P$-value \\
\hline Participants (n) & 35 & 17 & & 49 & 19 & \\
\hline Age (years) & $62.1 \pm 5.8$ & $63.2 \pm 4.76$ & 0.53 & $61.5 \pm 7.9$ & $60.3 \pm 7.5$ & 0.53 \\
\hline $\operatorname{Sex}(M / F)$ & $18 / 17$ & $13 / 4$ & 1.00 & $30 / 19$ & $15 / 4$ & 1.00 \\
\hline $\mathrm{FEV}_{1}$ (\% pred) & $107 \pm 14$ & $111 \pm 15$ & 0.34 & $54 \pm 22$ & $59 \pm 17$ & 0.53 \\
\hline BMI $\left(\mathrm{kg} / \mathrm{m}^{2}\right)$ & $25.9 \pm 2.8$ & $26.5 \pm 2.4$ & 0.40 & $25.5 \pm 4.5$ & $25.4 \pm 2.7$ & 0.94 \\
\hline Tobacco smoke (pack-years) & $5.5 \pm 10.4$ & $7.5 \pm 11.4$ & 0.55 & $44.3 \pm 19$ & $46.3 \pm 17.6$ & 0.71 \\
\hline Voorrips score & $4.6(2.4-7.1)$ & $3.8(2.1-7.0)$ & 0.55 & 4.I (2.2-7.2) & $4.9(3.5-6.4)$ & 0.79 \\
\hline 6MWD (\% pred) & $97 \pm 12$ & $10 I \pm I I$ & 0.29 & $78 \pm 18$ & $83 \pm 14$ & 0.231 \\
\hline $\mathrm{VO}_{2 S \mathrm{~L}}(\%$ pred $)$ & $107 \pm 14$ & $110 \pm 12$ & 0.51 & $68 \pm 19$ & $70 \pm 17$ & 0.60 \\
\hline Resting SP (mmHg) & $132 \pm 18$ & $|3| \pm 17$ & 0.86 & $132 \pm 23$ & $130 \pm 17$ & 0.70 \\
\hline Resting DP $(\mathrm{mmHg})$ & $80 \pm 10$ & $80 \pm 10$ & 0.92 & $79 \pm 11$ & $79 \pm 8$ & 0.97 \\
\hline Maximum SP (mmHg) & $203 \pm 25$ & $216 \pm 15$ & 0.06 & $200 \pm 31$ & $208 \pm 21$ & 0.35 \\
\hline Maximum DP $(\mathrm{mmHg})$ & $89 \pm 10$ & $93 \pm 9$ & 0.23 & $94 \pm 14$ & $97 \pm 14$ & 0.40 \\
\hline
\end{tabular}

Note: Data are presented as mean \pm SD, median (IQR: $25 \%-75 \%$ ), or $\mathrm{n}$.

Abbreviations: BMI, body mass index; DP, diastolic pressure; F, female; FEV , forced expiratory volume in I second; IQR, interquartile range; M, male; 6MWD, 6-minute walking distance; $\mathrm{VO}_{2 \mathrm{SL}}$, symptom-limited oxygen uptake; pred, predicted; SP, systolic pressure.
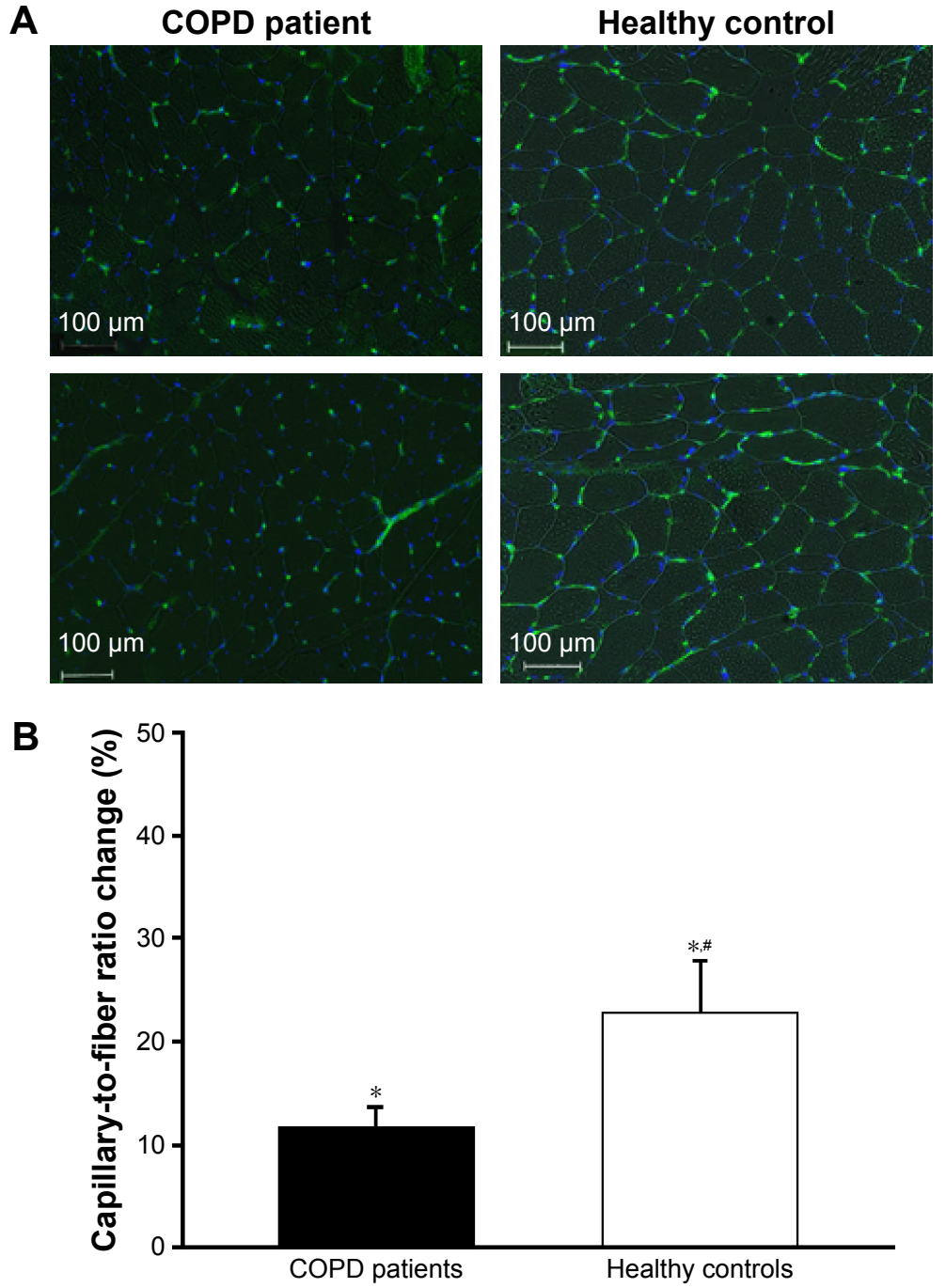

Figure I (A) Representative pictures of vastus lateralis myofibers (after Hoechst nuclei staining, blue) and capillaries (after staining for endothelial marker CD3 I, green) in a COPD patient and a control subject before (upper row) and after (lower row) training. (B) Mean values for the relative C/F ratio changes (\%) in COPD patients and healthy controls after training. "Group-time interaction $(P<0.05)$. *Time effect $(P<0.05)$.

Abbreviation: C/F, capillary-to-fiber. 

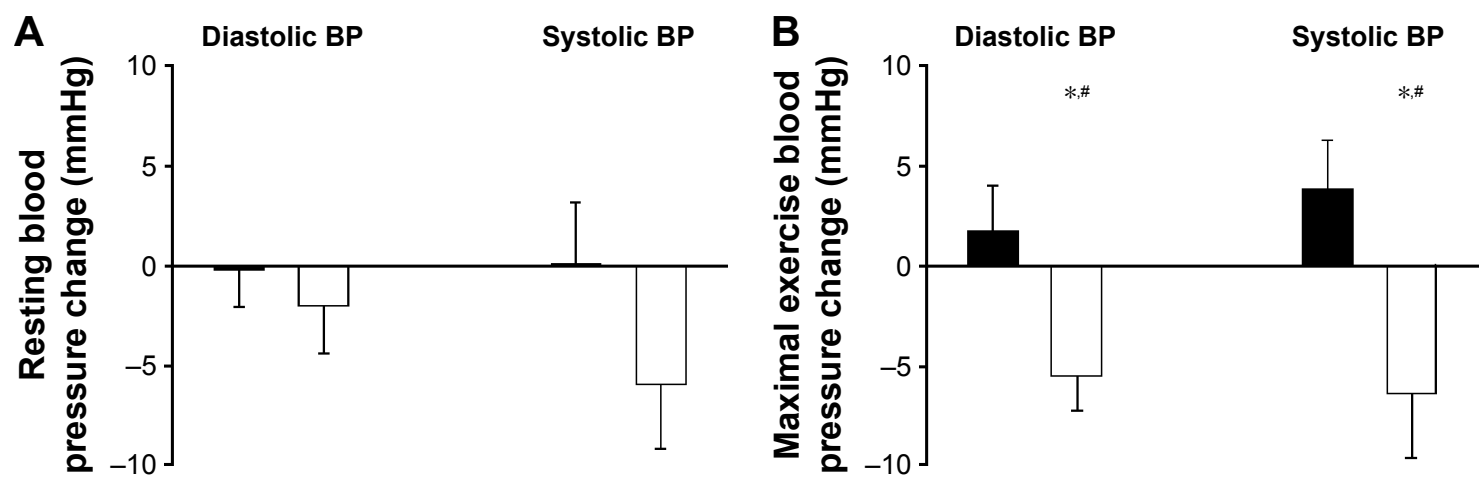

Healthy controls

COPD patients

Figure 2 (A) Mean and standard error of the mean of changes in resting DP (left) and SP (right) in COPD patients and healthy controls post-training. (B) Mean and standard error of the mean of changes in maximal exercise DP (left) and SP (right) in COPD patients and healthy controls post-training. ${ }^{*} \mathrm{Group}-$ time interaction $(P<0.05)$. ${ }^{*}$ Time effect $(P<0.05)$.

Abbreviations: BP, blood pressure; DP, diastolic pressure; SP, systolic pressure.

Posttraining maximal BP at similar maximum HR $(160 \pm 13 \mathrm{bpm}$ vs $162 \pm 12 \mathrm{bpm} ; P=0.41)$ was significantly reduced in CSs (DP: $89 \pm 10 \mathrm{mmHg}$ vs $85 \pm 9 \mathrm{mmHg}$; $P<0.001 /$ SP: $204 \pm 25 \mathrm{mmHg}$ vs $196 \pm 27 \mathrm{mmHg} ; P<0.05)$ but did not change significantly in COPD patients (DP: $94 \pm 14 \mathrm{mmHg}$ vs $97 \pm 16 \mathrm{mmHg} ; P=0.46 / \mathrm{SP}: 202 \pm 27 \mathrm{mmHg}$ vs $208 \pm 24 \mathrm{mmHg} ; P=0.13$ ). Maximal DP and SP showed significant interaction between group and time $(P<0.05$ for DP and SP), meaning that the training effect on BP significantly differed between groups. Maximal exercise pulsed pressure did not significantly change in either CSs $(114 \pm 21 \mathrm{mmHg}$ vs $111 \pm 24 \mathrm{mmHg} ; P=0.47)$ or COPD patients $(108 \pm 24 \mathrm{mmHg}$ vs $111 \pm 24 \mathrm{mmHg} ; P=0.58)$. Conversely, maximal MAP was significantly reduced in CSs $(127 \pm 13 \mathrm{mmHg}$ vs $121 \pm 13 \mathrm{mmHg} ; P<0.001)$ but not in COPD patients $(130 \pm 16 \mathrm{mmHg}$ vs $134 \pm 16 \mathrm{mmHg}$; $P=0.25$ ), with a significant interaction between group and time $(P<0.05)$.

\section{Relationships between resting and maximal exercise BP and determinants of systemic hypertension}

Resting and maximal exercise BP changes were not significantly correlated with changes in weight or $\mathrm{VO}_{2 \mathrm{SL}}$. In addition, baseline tobacco smoking in pack-years was not correlated with baseline BP or BP changes (Table 3). Maximal BP changes in males and females were not statistically different in either CSs $(-7.8 \pm 9.9 \mathrm{mmHg}$ vs $-3.5 \pm 9.0 \mathrm{mmHg}$ and $-10.2 \pm 18.2 \mathrm{mmHg}$ vs $-2.9 \pm 16.1 \mathrm{mmHg}$ for SP and DP, respectively) or COPD patients $(2.8 \pm 14.5 \mathrm{mmHg}$ vs $-0.06 \pm 16.8 \mathrm{mmHg}$ and

Table 3 Correlation coefficients and $P$-values between resting and maximal exercise blood pressure and usual risk factors for HTA

\begin{tabular}{|c|c|c|c|c|}
\hline Characteristics & $\begin{array}{l}\text { Changes in } \\
\text { resting DP }\end{array}$ & $\begin{array}{l}\text { Changes in } \\
\text { resting SP }\end{array}$ & $\begin{array}{l}\text { Changes in } \max \\
\text { exercise DP }\end{array}$ & $\begin{array}{l}\text { Changes in max } \\
\text { exercise SP }\end{array}$ \\
\hline \multirow[t]{2}{*}{ Age (years) } & -0.04 & 0.08 & 0.02 & -0.09 \\
\hline & 0.73 & 0.49 & 0.85 & 0.43 \\
\hline \multirow[t]{2}{*}{ BMI $\left(\mathrm{kg} / \mathrm{m}^{2}\right)$} & -0.15 & 0.11 & -0.02 & -0.11 \\
\hline & 0.19 & 0.35 & 0.84 & 0.37 \\
\hline \multirow[t]{2}{*}{$\mathrm{VO}_{2 \mathrm{LL}}(\%$ pred $)$} & -0.07 & -0.29 & 0.15 & -0.09 \\
\hline & 0.63 & 0.05 & 0.35 & 0.57 \\
\hline Physical activity level & 0.05 & -0.01 & 0.10 & 0.21 \\
\hline (Voorrips score) & 0.70 & 0.92 & 0.44 & 0.07 \\
\hline Tobacco smoking & -0.16 & 0.03 & 0.08 & 0.22 \\
\hline (pack-years) & 0.20 & 0.81 & 0.53 & 0.07 \\
\hline \multirow[t]{2}{*}{ Changes in weight $(\mathrm{kg})$} & 0.02 & 0.07 & -0.08 & 0.04 \\
\hline & 0.89 & 0.57 & 0.49 & 0.74 \\
\hline \multirow[t]{2}{*}{ Changes in $\mathrm{VO}_{2 S L}(\%$ pred $)$} & 0.10 & 0.02 & 0.00 & -0.04 \\
\hline & 0.41 & 0.72 & 0.97 & 0.73 \\
\hline
\end{tabular}

Notes: The correlations between the variables are presented by Pearson's correlation coefficients or Spearman's rank correlation coefficients. For each characteristic the correlation coefficients are shown on the top line and the $P$-values are shown on the bottom line.

Abbreviations: BMI, body mass index; DP, diastolic pressure; HTA, arterial hypertension; max, maximum; pred, predicted; SP, systolic pressure; VO ${ }_{2 \mathrm{~S}}$, symptom-limited oxygen uptake. 

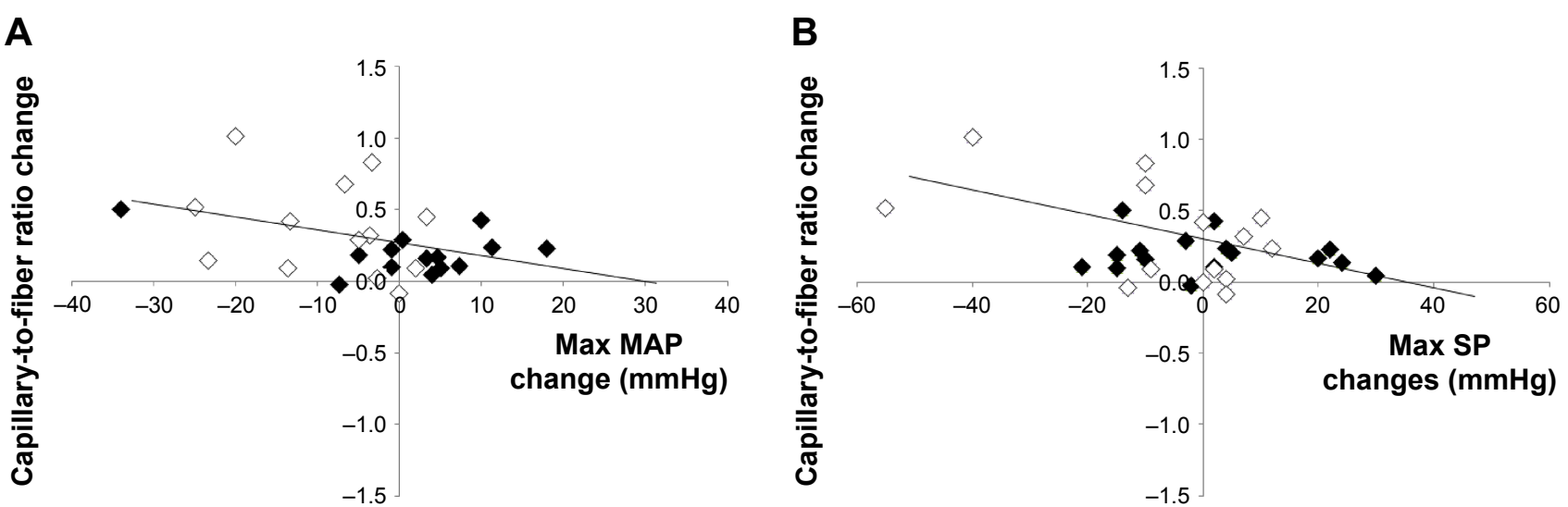

$\diamond \mathrm{SHS} \diamond \mathrm{COPD}$ patients

Figure $3(\mathbf{A})$ The $\mathrm{C} / \mathrm{F}$ ratio changes were negatively correlated with the changes in maximal exercise MAP $(r=-0.37, P=0.06)$ in $\mathrm{COPD}$ patients and healthy controls posttraining. (B) The C/F ratio changes were negatively correlated with the changes in maximal exercise $S P(r=-0.4 I, P<0.05)$ in COPD patients and CSs post-training. Abbreviations: C/F, capillary-to-fiber; CSs, control subjects; Max, maximum; MAP, mean arterial pressure; SP, systolic pressure.

$1.9 \pm 17.6 \mathrm{mmHg}$ vs $6.9 \pm 16.3 \mathrm{mmHg}$ for SP and DP, respectively). Figure 3 shows the significant negative correlations between maximal SP and MAP and $\mathrm{C} / \mathrm{F}$ ratio changes in the pooled CSs and COPD patients $(r=-0.41$ and $r=-0.37$ for maximum MAP and SP; $P=0.02$ and $P=0.06$, respectively).

\section{Discussion}

Our results show that an efficient exercise training program significantly reduced maximal exercise BP in matched CSs but not in COPD patients. The blunted adaptation of the muscle capillary bed may have been a factor in this lack of improved BP in the patients.

\section{Effect of exercise training on BP in healthy subjects and COPD patients}

Our study is the first to demonstrate impaired BP adaptation to exercise training in COPD patients. Three earlier studies $^{23,24,31,32}$ showed no improvement in resting BP, but a recent meta-analysis reported that the training-induced $\mathrm{BP}$ change in the subgroup of normotensive subjects was very low $\left(-0.75 \mathrm{mmHg}\right.$ and $-1 \mathrm{mmHg}$ for SP and DP, respectively). ${ }^{11}$ Therefore, the lack of significant posttraining improvement in resting BP in the COPD patients could not be attributed to the disease, but rather to a lack of power. Notably, however, the one study with a large cohort of COPD patients showing no training-induced improvement in resting BP did not compare the results with matched healthy CSs. ${ }^{31}$

In addition, in agreement with the abovementioned metaanalysis, ${ }^{11}$ training-induced BP declines have only been observed in studies that included COPD patients presenting elevated resting BP values. ${ }^{33,34}$ These observations indicate that training-induced BP changes occur in COPD patients with advanced vascular disease. Therefore, the lack of improvement in resting BP in our COPD patients with normal resting $\mathrm{BP}$ is in line with the published data. ${ }^{11}$

\section{Effect of exercise training on BP in COPD patients: potential biases of the study}

In contrast to CSs, COPD patients showed no decrease in maximal exercise BP after training. One strength of our study was the control of biases. At baseline, the HTA prevalence in CSs and COPD patients was similar to that observed in the general population ${ }^{35}$ and large cohorts. ${ }^{2,23}$ Although HTA was more prevalent in COPD patients, resting BP was not different between groups. In addition, both groups were matched for HTA risk factors: age, BMI, and physical inactivity. The sex ratio did not differ statistically between groups. Furthermore, the differential resting and exercise BP changes after training cannot be imputed to differences in sex, metabolic effects, or training regimens, because the exercise BP changes in both CSs and COPD patients showed no sex difference, and weight and aerobic capacity changes were not correlated with maximal BP changes in either group.

Overall, cumulative tobacco smoking and HTA prevalence were the only factors that differed between controls and COPD patients. Yet, cumulative tobacco smoking was not correlated with baseline BP or BP changes.

\section{Microvascular training effects in healthy subjects}

In healthy subjects, the major site of total peripheral resistance is not the large arteries but the microcirculation. ${ }^{8,36}$ 
Capillary rarefaction, which is the consequence of arteriolar vasoconstriction (functional rarefaction) or capillary destruction (structural rarefaction), is pathognomonic of essential hypertension. Both functional and structural rarefactions have been reported in skin tissue from hypertensive patients ${ }^{37}$ and in healthy subjects with exercise-induced HTA. ${ }^{16}$ Functional rarefaction can induce structural rarefaction in spontaneously hypertensive rats. ${ }^{38}$ Moreover, structural capillary rarefaction may be a causal factor of HTA. ${ }^{8,36}$ Indeed, rarefaction occurs early in the development of HTA and has been detected in normotensive individuals with familial predisposition. ${ }^{39}$ Infants born from hypertensive mothers have significantly lower maximal capillary density than those born from normotensive mothers. ${ }^{40}$ In addition, mathematical modeling suggests that capillary rarefaction can amplify an initial increase in BP. ${ }^{41}$

Conversely, experimental interventions improving the capillary bed in animal models (ovariectomy or training ${ }^{9}$ ) have improved BP in spontaneously hypertensive rats. In our study, we observed an improvement in maximal exercise $\mathrm{BP}$ and MAP (with no change in its pulsatile component), indicating a reduction in peripheral vascular resistance (as expected ${ }^{42}$ ) and a concomitant structural increase in the capillary bed (as observed earlier ${ }^{17}$ ). Therefore, our training program induced a significant microvascular improvement in our healthy controls.

\section{Vascular training effects in COPD patients}

The impaired improvement in maximal exercise BP in COPD patients may have been due to no improvement in large artery stiffness. ${ }^{23}$ However, this observation has not been consistently reported..$^{22,34,43,44}$ Given the observation in our healthy controls, impaired BP adaptations to training in COPD patients are at least microvascular. Indeed, after a similar exercise training program performed at a similar relative intensity, the $\mathrm{C} / \mathrm{F}$ increase was significantly lower in COPD patients vs matched CSs, confirming earlier results in a larger population. ${ }^{18}$ In addition, the $\mathrm{C} / \mathrm{F}$ changes were significantly correlated with maximal exercise SP and MAP in both CSs and COPD patients.

Although a lack of training-induced development of the capillary bed may directly impair exercise BP in COPD patients, arterioles may also be a link between the blunted BP and capillary changes in these patients. In healthy subjects, arteriolar vasodilatation leads to capillary recruitment and triggers structural angiogenesis. ${ }^{36}$ Exercise training physiologically improves flow-mediated vasodilatation and muscle hyperemia during exercise. ${ }^{10}$ In COPD patients, however, arteriolar flow-mediated vasodilatation is impaired ${ }^{45,46}$ and exercise training may not improve it, resulting in the blunted reduction of exercise BP and lack of muscle capillarization. However, flow-mediated vasodilatation is increased in physically active vs sedentary COPD patients. ${ }^{45}$

Blunted capillary angiogenesis appears to be a viable hypothesis for the lack of reduction in exercise BP and peripheral vascular resistance in COPD patients after training. The oxidative stress, which is implicated in the cardiovascular comorbidities of COPD patients, ${ }^{47}$ can trigger endothelial apoptosis in HTA rats ${ }^{48}$ and COPD patients. ${ }^{49}$ In addition, oxidative stress reduces the mobilization of the endothelial progenitor cells that have angiogenic properties, ${ }^{50}$ in particular, after training. ${ }^{51}$ Therefore, oxidative stress may be the link between impaired training-induced BP changes and capillarization in COPD patients.

\section{Conclusion}

Our comparative analysis of training responses in COPD patients vs matched CSs reveals defective maximal exercise BP adaptation in patients associated with reduced improvement in muscle capillarization. Further studies are needed to explore the possibility of blunted angiogenesis and other mechanisms involved in a "microangiogenic disease" in COPD patients.

\section{Acknowledgments}

The authors gratefully acknowledge A Bourret and G Hugon for their technical support in the laboratory and all of the team from "La Solane" and "La Vallonie" Pulmonary Rehabilitation Centers for their contribution to this work. Nicolas Molinari is acknowledged for the statistical analysis and C Stott for a critical reading of the manuscript. L Ducros is acknowledged for the critical analysis of muscle capillarization. This study was supported by joint grants from the Centre Hospitalier Universitaire (CHU) and the patient association, Association pour l'Assistance Respiratoire au Domicile.

\section{Author contributions}

FG contributed to the study conception and design, had full access to all data, took full responsibility for the integrity and accuracy of the data analysis, drafted the submitted article, and provided final approval of the version to be published. JMa, FB, MB, BA, JMe, APM, PP, and MH contributed substantially to the study design, data analysis, and interpretation of the manuscript, revised the manuscript critically for important intellectual content, and provided final approval of the version to be published. 


\section{Disclosure}

J Maury was supported by a "CIFRE grant" (Conventions Industrielles de Formation par la Recherche [Industrial agreements for training through research]) from the 5 Santé/ Fontalvie Corporation, Toulouges, France, and the French "Ministère délégué à la recherche et aux nouvelles technologies" [French Ministry of Higher Education and Scientific Research]. The other authors report no conflicts of interest in this work.

\section{References}

1. Allison TG, Cordeiro MA, Miller TD, Daida H, Squires RW, Gau GT. Prognostic significance of exercise-induced systemic hypertension in healthy subjects. Am J Cardiol. 1999;83(3):371-375.

2. Park HJ, Leem AY, Lee SH, et al. Comorbidities in obstructive lung disease in Korea: data from the fourth and fifth Korean National Health and Nutrition Examination Survey. Int J Chron Obstruct Pulmon Dis. 2015;10:1571-1582.

3. Vanfleteren LE, Spruit MA, Groenen M, et al. Clusters of comorbidities based on validated objective measurements and systemic inflammation in patients with chronic obstructive pulmonary disease. Am J Respir Crit Care Med. 2013;187(7):728-735.

4. Chen W, Thomas J, Sadatsafavi M, FitzGerald JM. Risk of cardiovascular comorbidity in patients with chronic obstructive pulmonary disease: a systematic review and meta-analysis. Lancet Respir Med. 2015;3(8):631-639.

5. Sin DD, Anthonisen NR, Soriano JB, Agusti AG. Mortality in COPD: role of comorbidities. Eur Respir J. 2006;28(6):1245-1257.

6. Divo M, Cote C, de Torres JP, et al. Comorbidities and risk of mortality in patients with chronic obstructive pulmonary disease. Am J Respir Crit Care Med. 2014;186(2):155-161.

7. Rabahi MF, Pereira SA, Silva Junior JL, et al. Prevalence of chronic obstructive pulmonary disease among patients with systemic arterial hypertension without respiratory symptoms. Int J Chron Obstruct Pulmon Dis. 2015;10:1525-1529.

8. Triantafyllou A, Anyfanti P, Pyrpasopoulou A, Triantafyllou G, Aslanidis S, Douma S. Capillary rarefaction as an index for the microvascular assessment of hypertensive patients. Curr Hypertens Rep. 2015; 17(5):33.

9. Guo Q, Minami N, Mori N, et al. Effects of estradiol, angiotensinconverting enzyme inhibitor and exercise training on exercise capacity and skeletal muscle in old female rats. Clin Exp Hypertens. 2010;32(2):76-83.

10. Calbet JA, Lundby C. Skeletal muscle vasodilatation during maximal exercise in health and disease. $J$ Physiol. 2012;590(pt 24): 6285-6296.

11. Cornelissen VA, Smart NA. Exercise training for blood pressure: a systematic review and meta-analysis. $J$ Am Heart Assoc. 2013;2(1): e004473.

12. Lauer MS, Pashkow FJ, Harvey SA, Marwick TH, Thomas JD. Angiographic and prognostic implications of an exaggerated exercise systolic blood pressure response and rest systolic blood pressure in adults undergoing evaluation for suspected coronary artery disease. J Am Coll Cardiol. 1995;26(7):1630-1636.

13. Sharman JE, Hare JL, Thomas S, et al. Association of masked hypertension and left ventricular remodeling with the hypertensive response to exercise. Am J Hypertens. 2011;24(8):898-903.

14. Miyai N, Arita M, Miyashita K, Morioka I, Shiraishi T, Nishio I. Blood pressure response to heart rate during exercise test and risk of future hypertension. Hypertension. 2002;39(3):761-766.

15. Schultz MG, Otahal P, Cleland VJ, Blizzard L, Marwick TH, Sharman JE. Exercise-induced hypertension, cardiovascular events, and mortality in patients undergoing exercise stress testing: a systematic review and meta-analysis. Am J Hypertens. 2013;26(3):357-366.
16. Ciuffetti G, Schillaci G, Innocente S, et al. Capillary rarefaction and abnormal cardiovascular reactivity in hypertension. J Hypertens. 2003; 21(12):2297-2303.

17. Gliemann L, Buess R, Nyberg M, et al. Capillary growth, ultrastructure remodelling and exercise training in skeletal muscle of essential hypertensive patients. Acta Physiol (Oxf). 2015;214(2):210-220.

18. Gouzi F, Prefaut C, Abdellaoui A, et al. Blunted muscle angiogenic training-response in COPD patients versus sedentary controls. Eur Respir J. 2013;41(4):806-814.

19. Whittom F, Jobin J, Simard PM, et al. Histochemical and morphological characteristics of the vastus lateralis muscle in patients with chronic obstructive pulmonary disease. Med Sci Sports Exerc. 1998;30(10): $1467-1474$.

20. Eliason G, Abdel-Halim SM, Piehl-Aulin K, Kadi F. Alterations in the muscle-to-capillary interface in patients with different degrees of chronic obstructive pulmonary disease. Respir Res. 2010;11:97.

21. Gagnon P, Lemire BB, Dube A, et al. Preserved function and reduced angiogenesis potential of the quadriceps in patients with mild COPD. Respir Res. 2014;15:4.

22. Vivodtzev I, Tamisier R, Baguet JP, Borel JC, Levy P, Pepin JL. Arterial stiffness in COPD. Chest. 2014;145(4):861-875.

23. Vanfleteren LE, Spruit MA, Groenen MT, et al. Arterial stiffness in patients with COPD: the role of systemic inflammation and the effects of pulmonary rehabilitation. Eur Respir J. 2014;43(5):1306-1315.

24. Costes F, Roche F, Pichot V, Vergnon JM, Garet M, Barthelemy JC. Influence of exercise training on cardiac baroreflex sensitivity in patients with COPD. Eur Respir J. 2004;23(3):396-401.

25. Rabe KF, Hurd S, Anzueto A, et al. Global strategy for the diagnosis, management, and prevention of chronic obstructive pulmonary disease: GOLD executive summary. Am J Respir Crit Care Med. 2007;176(6): 532-555.

26. Filipovsky J, Ducimetiere P, Safar ME. Prognostic significance of exercise blood pressure and heart rate in middle-aged men. Hypertension. 1992;20(3):333-339.

27. VoorripsLE, RavelliAC, Dongelmans PC, DeurenbergP, VanStaverenWA. A physical activity questionnaire for the elderly. Med Sci Sports Exerc. 1991;23(8):974-979.

28. Hayot M, Michaud A, Koechlin C, et al. Skeletal muscle microbiopsy: a validation study of a minimally invasive technique. Eur Respir $J$. 2005;25(3):431-440.

29. Vallet G, Ahmaidi S, Serres I, et al. Comparison of two training programmes in chronic airway limitation patients: standardized versus individualized protocols. Eur Respir J. 1997;10(1):114-122.

30. Nici L, Donner C, Wouters E, et al. American Thoracic Society/ European Respiratory Society statement on pulmonary rehabilitation. Am J Respir Crit Care Med. 2006;173(12):1390-1413.

31. Canavan JL, Kaliaraju D, Nolan CM, et al. Does pulmonary rehabilitation reduce peripheral blood pressure in patients with chronic obstructive pulmonary disease? Chron Respir Dis. 2015;12(3): 256-263.

32. Marquis K, Maltais F, Lacasse Y, Lacourciere Y, Fortin C, Poirier P. Effects of aerobic exercise training and irbesartan on blood pressure and heart rate variability in patients with chronic obstructive pulmonary disease. Can Respir J. 2008;15(7):355-360.

33. Reis LF, Guimaraes FS, Fernandes SJ, et al. A long-term pulmonary rehabilitation program progressively improves exercise tolerance, quality of life and cardiovascular risk factors in patients with COPD. Eur J Phys Rehabil Med. 2013;49(4):491-497.

34. Gale NS, Duckers JM, Enright S, Cockcroft JR, Shale DJ, Bolton CE. Does pulmonary rehabilitation address cardiovascular risk factors in patients with COPD? BMC Pulm Med. 2011;11:20.

35. Karam C, Beauchet A, Czernichow S, et al. Trends in cardiovascular disease risk factor prevalence and estimated 10-year cardiovascular risk scores in a large untreated French urban population: the CARVAR 92 study. PLoS One. 2015;10(4):e0124817.

36. Levy BI, Schiffrin EL, Mourad JJ, et al. Impaired tissue perfusion: a pathology common to hypertension, obesity, and diabetes mellitus. Circulation. 2008;118(9):968-976. 
37. Serne EH, Gans RO, ter Maaten JC, Tangelder GJ, Donker AJ, Stehouwer CD. Impaired skin capillary recruitment in essential hypertension is caused by both functional and structural capillary rarefaction. Hypertension. 2001;38(2):238-242.

38. Prewitt RL, Chen II, Dowell R. Development of microvascular rarefaction in the spontaneously hypertensive rat. Am J Physiol. 1982;243(2): $\mathrm{H} 243-\mathrm{H} 251$.

39. Antonios TF, Rattray FM, Singer DR, Markandu ND, Mortimer PS, MacGregor GA. Rarefaction of skin capillaries in normotensive offspring of individuals with essential hypertension. Heart. 2003;89(2): 175-178.

40. Antonios TF, Raghuraman RP, D'Souza R, Nathan P, Wang D, Manyonda IT. Capillary remodeling in infants born to hypertensive pregnancy: pilot study. Am J Hypertens. 2012;25(8):848-853.

41. Pries AR, Secomb TW, Gaehtgens P. Structural autoregulation of terminal vascular beds: vascular adaptation and development of hypertension. Hypertension. 1999;33(1):153-161.

42. Mortensen SP, Svendsen JH, Ersboll M, Hellsten Y, Secher NH, Saltin B. Skeletal muscle signaling and the heart rate and blood pressure response to exercise: insight from heart rate pacing during exercise with a trained and a deconditioned muscle group. Hypertension. 2013; 61(5):1126-1133.

43. Vivodtzev I, Minet C, Wuyam B, et al. Significant improvement in arterial stiffness after endurance training in patients with COPD. Chest. 2010;137(3):585-592.
44. Sievi NA, Franzen D, Kohler M, Clarenbach CF. Physical inactivity and arterial stiffness in COPD. Int J Chron Obstruct Pulmon Dis. 2015; 10:1891-1897.

45. Clarenbach CF, Senn O, Sievi NA, et al. Determinants of endothelial function in patients with COPD. Eur Respir J. 2013;42(5):1194-1204.

46. Ives SJ, Harris RA, Witman MA, et al. Vascular dysfunction and chronic obstructive pulmonary disease: the role of redox balance. Hypertension. 2014;63(3):459-467.

47. Maclay JD, MacNee W. Cardiovascular disease in COPD: mechanisms. Chest. 2013;143(3):798-807.

48. Kobayashi N, DeLano FA, Schmid-Schonbein GW. Oxidative stress promotes endothelial cell apoptosis and loss of microvessels in the spontaneously hypertensive rats. Arterioscler Thromb Vasc Biol. 2005; 25(10):2114-2121.

49. Thomashow MA, Shimbo D, Parikh MA, et al. Endothelial microparticles in mild chronic obstructive pulmonary disease and emphysema. The Multi-Ethnic Study of Atherosclerosis Chronic Obstructive Pulmonary Disease study. Am J Respir Crit Care Med. 2013;188(1):60-68.

50. Pizarro S, Garcia-Lucio J, Peinado VI, et al. Circulating progenitor cells and vascular dysfunction in chronic obstructive pulmonary disease. PLoS One. 2014;9(8):e106163.

51. Fernandes T, Nakamuta JS, Magalhaes FC, et al. Exercise training restores the endothelial progenitor cells number and function in hypertension: implications for angiogenesis. J Hypertens. 2012;30(11) 2133-2143.
International Journal of COPD

\section{Publish your work in this journal}

The International Journal of COPD is an international, peer-reviewed journal of therapeutics and pharmacology focusing on concise rapid reporting of clinical studies and reviews in COPD. Special focus is given to the pathophysiological processes underlying the disease, intervention programs, patient focused education, and self management protocols.

\section{Dovepress}

This journal is indexed on PubMed Central, MedLine and CAS. The manuscript management system is completely online and includes a very quick and fair peer-review system, which is all easy to use. Visit http://www.dovepress.com/testimonials.php to read real quotes from published authors. 